\title{
Antimicrobial Hydrogel Contact Lens Containing Alginate
}

\author{
Hyun Mee Lee, ${ }^{\dagger}$ Jong-Ki Kim, ${ }^{\ddagger}$ and Tae-Sub Cho ${ }^{*}$ \\ Department of Chemistry, College of Sciences, Yeungnam University, Gyeongbuk 712-749, Korea. ${ }^{*}$ E mail: tscho@yu.ac.kr \\ 'Department of Optometry \& Vision Science, College of Health and Medical Science, Catholic University of Daegu, \\ Gyeongbuk 712-702, Korea \\ "Department of Biomedical Engineering, School of Medicine, Catholic University of Daegu, Daegu 705-034, Korea \\ Received May 30, 2011, Accepted October 7, 2011
}

\begin{abstract}
Biocompatible hydrogels from 2-hydroxyethyl methacrylate (HEMA) monomer containing various amount of alginate in the presence and absence of hydrophilic methacrylic acid (MAA) were synthesized in order for biomedical application. The antimicrobial effect and interaction with proteins for hydrogels were investigated in this study. MAA was introduced because it was expected to increase the amount of water content in the polymer which is an important factor for biocompatibility, and alginate was expected to enhance the antimicrobial activity. The antimicrobial effect against $S$. aureus and E. coli increased for all hydrogels as the amount of alginate and MAA contained. Presence of MAA further enhances the antimicrobial effect. Amount of adsorption of bovine serum albumin (BSA) increased with increasing concentration of alginate whether MAA was present or not. Contrarily, the amount of lysozyme was not affected with increasing alginate concentration in the absence of MAA, while it decreased in the presence of MAA.
\end{abstract}

Key Words : Alginate, Hydrogel, Poly(2-hydroxyethyl methacylate), Methacrylic acid, Antimicrobial

\section{Introduction}

The biocompatible polymeric materials play an increasingly important role in biology, medicine and pharmacy fields as promising biomaterials. ${ }^{1-5}$ In particular, hydrogels occupies an important portion among biomaterials due to their hydrophilicity and ability to absorb water without losing their viscoelasticity. ${ }^{6}$ Swelling behavior, mechanical properties, and biocompatiblility of the hydrogels should be evaluated for use of biomedical purposes. Poly(2-hydroxyethyl methacylate) (pHEMA), one of hydrogels, has variety of applications such as dental adhesives, contact lens, tissue engineering, and drug delivery system..$^{7-10}$ The properties of hydrogel can be easily modulated according to comonomers and cross-linker. Co-polymerization of 2-hydroxyethyl methacylate (HEMA) with monomers capable of establishing specific ionic or hydrophilic interactions with the drug molecules has been widely used to improve the release or loading behavior. ${ }^{11-13}$ For instance, the hydrogels containing the comonomers methacrylic acid (MAA) or NVP ( $N$-vinyl pyrrolidone) has been shown to be capable for a large amount of water. ${ }^{14-17}$ The HEMA that has been copolymerized with anionic monomers such as MAA to introduce charged moieties in the polymeric network was found to improve the biological performance of the material. ${ }^{10,18}$ For that reason, HEMA-MAA hydrogels are often used for soft hydrogel contact lens.

Biocompatibility has become the central request for the medical application of various materials and devices. As one of recent instance, natural polysaccharide was reported to increase biocompatible of the polyelectrolyte hydrogel and structurally strengthen polymer by the interpenetrated macromolecular structure. ${ }^{19-22}$ Materials obtained from sea weeds were applied to improve biocompatibility. The polysaccharides isolated from sea weeds performed a role by reactive oxygen species (ROS) scavengers, and other biological activities, such as anticoagulant, antithrombotic, antitumor, anti-inflammatory, antimicrobial, and antioxidant activity. ${ }^{23-26}$ Alginic acid is an anionic polysaccharide from brown algae. Amphiphilic derivatives of sodium alginate, prepared by chemical covalent binding of long alkyl chains onto the polysaccharide backbone via ester functions, form strong hydrogels in aqueous solutions. The alginate hydrogels have been proved to have a wide variety of applicability as biomaterials. Alginate has been widely used also for cell immobilization and encapsulation, owing to its biocompatibility and simple gelation with divalent cations such as $\mathrm{Ca}^{2+}$. Alginate hydrogels have been used as footholds for tissue engineering, as delivery vehicles for drugs, and as model extracellular matrices for basic biological studies. ${ }^{27}$ Biofilms are collections of microorganisms encased in a matrix that is often composed of both bacterial and host materials. They form on natural surfaces such as heart valves or abiotic surfaces such as contact lenses or intraocular lenses. ${ }^{28}$ Until now, hydrogel biofilm containing alginate was not applied in contact lenses. For improving biocompatible biofilm and applying contact lens, we investigated the antimicrobial properties of hydrogel materials which have been surface modified by impregnation with alginate to biological activities, yielding candidate anti-infective hydrogel.

\section{Materials and Methods}

Materials. 2-Hydroxyethyl methacrylate (HEMA), meth- 
(a)

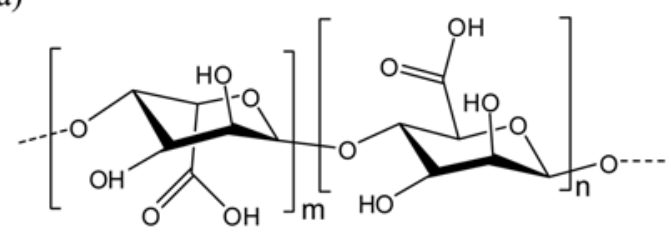

(b)<smiles>C=C(C)C(=O)OCCO</smiles>

(c)

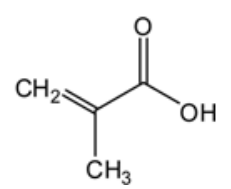

Figure 1. The chemical structures of (a) alginate, (b) HEMA, and (c) MAA.

acrylic acid (MAA), and ethylene glycol dimethacrylate (EGDMA) were purchased from Sigma-Aldrich Chemicals Co. Monomers were used without further purification. 2-2'azobisisobutyronitrile (AIBN) for initiator was obtained from Junsei Chemical Co. Alginic acid sodium salt was obtained from Sigma-Aldrich Chemicals Co. Protein, bovine serum albumin (BSA) and lysozyme from chicken eggwhite were obtained from Sigma Co for adsorption experiment. For antimicrobial effects, Staphyloccus aureus (S. aureus, ATCC 10537), Escherichia coli (E. coli, ATCC 47076) were purchased from Korean Culture Center of Microorganisms. The structures of the monomers and alginate are shown in Figure 1.

Hydrogels Synthesis. The hydrogels were synthesized by copolymerizing HEMA and MAA monomers in the presence of alginate solutions. The final concentrations of the EGDMA crosslinker and AIBN initiator were $0.3 \% \mathrm{v} / \mathrm{v}$, $0.1 \% \mathrm{v} / \mathrm{v}$ relative to HEMA, respectively. HEMA is the main composition of hydrogels. In order to estimate biological properties with respect to water content, the amounts of alginate were controlled $0-2 \% \mathrm{v} / \mathrm{v}$ in the absence or presence MAA. The compositions of hydrogels are summarized in Table 1. The mixed solutions were poured onto molds comprising two glasses plate covered internally with polypropylene sheets. The two glasses were separated by a 1 $\mathrm{mm}$ thick silicone frame. The samples were then placed in

Table 1. Percent compositions ${ }^{a}$ and water content ${ }^{\mathbf{b}}$ of samples (\%)

\begin{tabular}{ccccc}
\hline & HEMA & Alginate & MA & Water content \\
\hline S1 & 99.6 & 0 & 0 & $37.35 \pm 1.03$ \\
S2 & 99.1 & 0.5 & 0 & $37.70 \pm 0.97$ \\
S3 & 98.6 & 1 & 0 & $37.01 \pm 1.10$ \\
S4 & 97.6 & 2 & 0 & $36.68 \pm 1.22$ \\
S5 & 94.6 & 0 & 5 & $48.89 \pm 0.95$ \\
S6 & 94.1 & 0.5 & 5 & $50.93 \pm 0.76$ \\
S7 & 93.6 & 1 & 5 & $50.80 \pm 1.24$ \\
S8 & 92.6 & 2 & 5 & $50.57 \pm 1.55$ \\
\hline
\end{tabular}

${ }^{a}$ The values of composition have excepted EDGMA $(0.3 \%)$ and AIBN $(0.1 \%) .{ }^{b}$ Valued represent the mean \pm S.D. at least triplicate determination. an oven at $60{ }^{\circ} \mathrm{C}$ for overnight $(16 \mathrm{hr})$ and then heated at 80 ${ }^{\circ} \mathrm{C}$ for additional $1 \mathrm{hr}$. After polymerization, each hydrogel biofilm was immersed in hot distilled water for $30 \mathrm{~min}$ to remove unreacted monomers.

Transparency Measurement. The optical transparencies of the hydrogels were measured using a spectrophotometer (Cary 100) in the wavelength range of 250-750 $\mathrm{nm}$. The biofilms were immersed in $0.9 \% \mathrm{NaCl}$ solution for $24 \mathrm{hr}$ and inserted between two quartz slides for measurement. All transparencies were measured at room temperature.

The Equilibrium Water Content. The equilibrium water content (EWC) of the hydrogels was calculated as follows:

$$
\operatorname{EWC}(\%)=\frac{W_{\text {swell }}-W_{d r y}}{W_{\text {swell }}} \times 100
$$

Where $W_{\text {swell }}$ denotes swollen sample weight of the hydrogel which was swelled in a $0.9 \% \mathrm{NaCl}$ solution at room temperature for $24 \mathrm{hr}$. $W_{d r y}$ represents dried sample weight. Dried sample was obtained by drying the hydrogel for overnight at $100^{\circ} \mathrm{C}$.

Antimicrobial Activity. The antibacterial effect of HEMA hydrogel containing alginate was determined using Staphylococcus aureus (S. aureus) for gram-positive, and Escherichia coli (E. coli) for gram-negative. The preculture of cell was grown routinely in Luria-Bertani (LB) media in aerobic conditions at $37^{\circ} \mathrm{C}, 180 \mathrm{rpm} .0 .5 \mathrm{uL}$ of precultured solution was diluted to $5 \mathrm{~mL}$ LB media into which two discs $(0.3 \mathrm{~g})$ of biofilm was soaked. The antibacterial effect was tested using a spectrometer after $3,12,24,36$, and $48 \mathrm{hr}$. The optical densities were measured with time for 2 days at 600 nm.

Protein Adsorption. In order to estimate the amount of attached protein (adsorbed or covalently attached), the two discs $(0.3 \mathrm{~g})$ of hydrogels were soaked in phosphatebuffered saline (PBS, pH 7.4) for $4 \mathrm{hr}$. Then the hydrogels were immersed either in $3 \mathrm{~mL}$ of $3.88 \mathrm{~g} / \mathrm{L} \mathrm{BSA}$, or in $1.2 \mathrm{~g} / \mathrm{L}$ lysozyme solutions for $24 \mathrm{hr}$. The concentrations of the proteins were measured by spectrophotometer at $280 \mathrm{~nm}$ using the following extinction coefficients: $\varepsilon_{280 \mathrm{~nm}}=0.67$ $\mathrm{cm}^{-1} \mathrm{M}^{-1}, 2.64 \mathrm{~cm}^{-1} \mathrm{M}^{-1}$ for $1 \mathrm{mg} / \mathrm{mL}$ BSA and lysozyme, respectively. The equilibrium protein adsorption amount was determined according to follows;

$$
Q_{e}=\frac{V\left(C_{0}-C_{e}\right)}{m}
$$

Where $Q_{e}(\mathrm{mg} / \mathrm{g})$ is amount of protein adsorbed, and $V(\mathrm{~mL})$ is the volume of the solution. $C_{0}(\mathrm{mg} / \mathrm{mL})$ represents the initial concentration of protein in the solution and $C_{e}(\mathrm{mg} /$ $\mathrm{mL})$ is the equilibrium concentration of protein. $m(\mathrm{~g})$ denotes the mass of hydrogels.

\section{Results and Discussion}

Optical Transparency. Transparency is essential property for optical hydrogel. Effect of alginate on the transparency of biofilm to which alginate was introduced to enhance the capacity as the biomaterial of contact lens was investigated. 


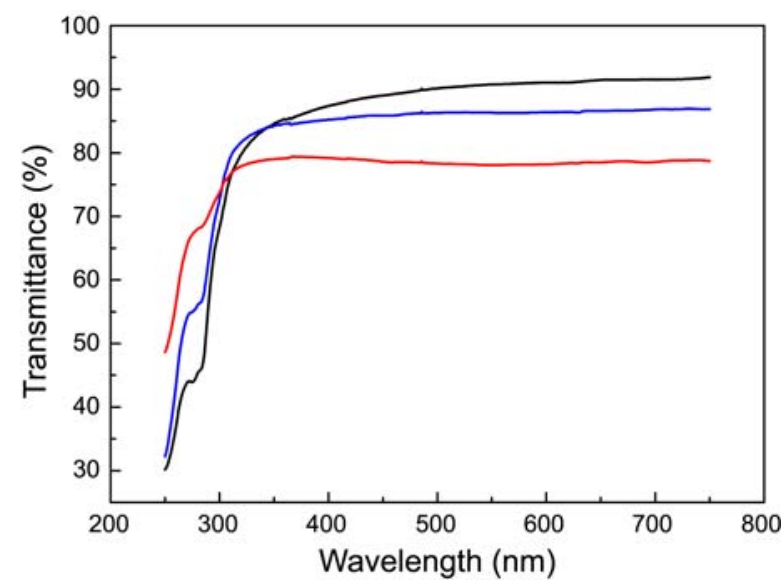

Figure 2. Optical transmittance of hydrogels. Black, blue, and red line indicated S1, S5, and S8, respectively.

The transparency of the samples S1, S5 and S8 are shown as the examples in Figure 2. In S1, only HEMA is present while S5 contains 5\% MAA and S5 contains additional 2\% alginate to HEMA-MAA. S1 showed approximately $90 \%$ transparency which decreases somewhat when MAA was contained. Addition of alginate resulted in further $10 \%$ decrease in the transparency being about $80 \%$ in all range. In the UV-C region, the transparency was in the range of $40 \%$, $50 \%$ and $60 \%$ for S1, S5 and S8, respectively. The transparency of HEMA increased in the presence of MAA compared to its absence. The presence of alginate resulted in an additional increase in the UV-C region. Overall, the transparencies of the biofilms synthesized in this study were in the acceptable range for usage of contact lens.

The Equilibrium Water Contents. pHEMA is a stable hydrogel polymer. The amount of water that contained in a hydrogel may be affected by temperature, $\mathrm{pH}$, and tonicity (osmolality or salt concentration). Water content has been known to affects the density, refractive index and permeability of oxygen. Higher the water contents, decreased density and refractive index, while better the permeability of oxygen. ${ }^{29}$ Thus, the water content is an important property as a biomaterial for contact lens. The water content of hydrogel depends on the nature of hydrophilic and hydrophobic functional groups of the monomer and the state of crosslink in the polymer. ${ }^{29-31}$ In this study, pHEMA was synthesized from HEMA. In the pHEMA, either MAA which increases the efficiency of water adsorption, or alginate extracted from sea weeds, or both were interpenetrated in order to enhance biocompatibility with various desirable abilities. The content of water depending on the MAA and/or alginate are summarized in Table 1 . The water content of the S1 which is pHEMA was $38 \%$ in accordance with general known values. The content of water showed tendency to decrease with increasing amount of alginate in the absent of MAA (S2-S4). In the presence of MAA, the amounts of contained water were $\sim 50 \%$ as it was expected. However, similarly in the case of absence of MAA, increasing amount of alginate resulted in decreases in the water content (S5-S8). The reason for decreasing water content may be the replacement of water molecule in the chain entanglements and the chains loop, which formed when the formation of the polymer, by alginate.

Adsorption Protein. Adsorption of protein on the soft hydrogel contact lens is an important problem. The proteins in the tears that can absorb on the surface of lens become the reason for deemed sight, putrefaction of lens, and itching. Therefore, the relationship of the quality of hydrogel and protein adsorption has been widely studied. Amount of protein adsorption is affected by type and concentration of hydrogel and protein, and $\mathrm{pH}$ of the media. Nature of binding, i.e., hydrogen bond, hydrophobic bond, hydrophilic bond, and electrostatic attraction affect the adsorption of protein. ${ }^{32-35}$ The protein adsorption causes the attachment of bacterium on the hydrogel lowing its quality. The relationship between the protein adsorption and bacteria adhesion, therefore, has been also widely studied. ${ }^{36-39}$ For this reason, amount of protein that adsorbed to contact lens hydrogel was measured in this study using representative proteins namely, BSA and lysozyme. The extent of protein adsorption to pHEMA with respect to the amount of alginate in the presence of an anionic hydrophilic monomer, MAA, and its absence were measured and the results are shown in Figure 3. The amount of BSA adsorbed to hydrogel was, in general, small being less than $5 \mathrm{mg} / \mathrm{g}$. In comparison of S1-S4 with S5-S8, the presence of MAA causes the somewhat less amount of adsorbed BSA. On the other hand, alginate a little enhances the noticeable amount of adsorbed BSA. The latter observation is in accordance with the report ${ }^{22}$ in the biomedical application of poly(HEMA-co-METAC)/alginate hydrogel. The amount of adsorption of lysozyme to hydrogel differs in large extent compared to BSA. In particular, large difference was noticed between the presence and absence of MAA. In the absence of MAA, the amount of lysozyme was similar to that of BSA, while surprisingly large amount of lysozyme was adsorbed in the presence. The presence of MAA caused the 4-10 times more lysozyme adsorption compared to BSA. It was also observed that increasing in the

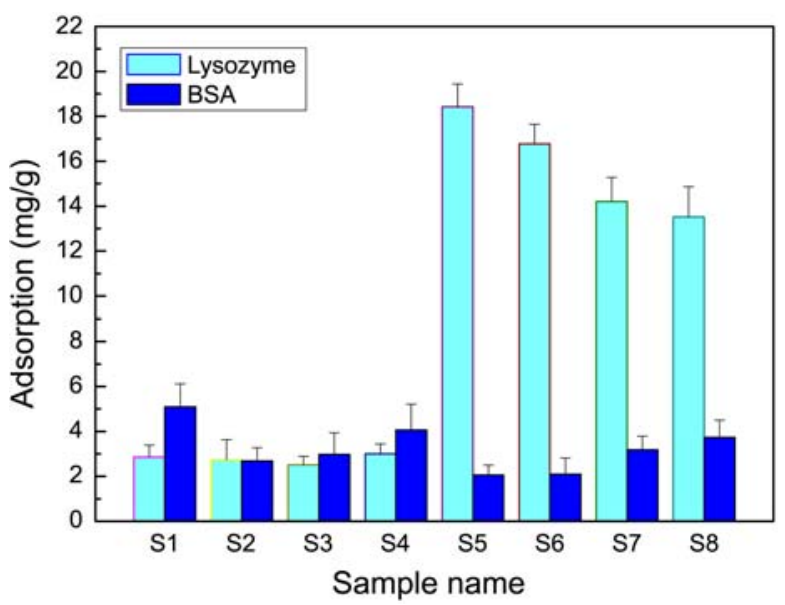

Figure 3. Protein adsorption of hydrogels by Bovine Serum Albumin (BSA) and Lysozyme. 
alginate amount did not enhanced extent of lysozyme adsorption in the absence of MAA. In contrast, alginate decreases the lysozyme adsorption in the presence of MAA. It is a general tendency that the increase in the hydrophilic monomer in the polymer results in a decreased protein adsorption. In other word, the high water content material exhibited less protein decomposition compared to low water content material. ${ }^{34,40}$ Water absorbance dependent protein deposition on hydrogel is caused by complex interactions between hydrogel, water, and protein. One of the important factors to be considered is the size and charge of hydrogel and the protein. In this study, lysozyme was shown to be easily adsorbed on the hydrogel containing hydrophilic monomer, MAA. The reason for easy adsorption is the electrostatic attraction and size of protein. Lysozyme bore a net positive charge at neutral $\mathrm{pH}$ due to its high isoelectric point (pI, 10.8). The negative charges on carboxyl group of MAA will easily attract the positive charges of lysozyme. In addition, small size of lysozyme allows easy insertion of the protein between the stems of the hydrogel polymer. ${ }^{41-45}$ There were strong interactions between lysozyme and monomer MAA, electrostatic interaction and hydrogen bonding, the lysozyme molecule-surface imprinting was successfully realized. ${ }^{46}$ The HEMA/MAA hydrogel have very high binding affinity for lysozyme.

The Antimicrobial Effect. The eyes require proper physiological moiety and temperature for normal functioning. They are sensitive for the stimuli from outside and are exposed to pathogenic bacterium. For these reasons, the cornea and cornea epithelial cell are easily damaged. The bacterial conjunctivitis also occurs frequently. The hydrogel contain high antimicrobial activity is obtain low absorbance value, however low antimicrobial activity of the hydrogels has high absorbance. According to the increasing bacteria number, absorbance has lower. The absorbance is significantly associated with antibacterial activity. We used two the bacterias, $S$. aureus and $E$. coli for antimicrobial activities in this study. The origin of these damage is the common bacterium including, $S$. aureus, $P$. aeruginosa, and E. coli. ${ }^{47,48}$ For this reason, the antimicrobial activities of the hydrogel,

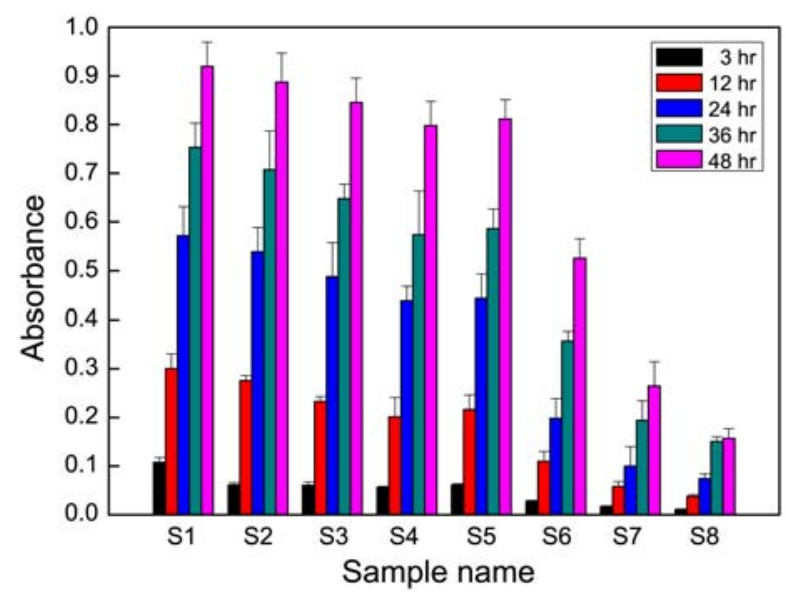

Figure 4. Antimicrobial activities of hydrogels for $S$. aureus during 48 hours.

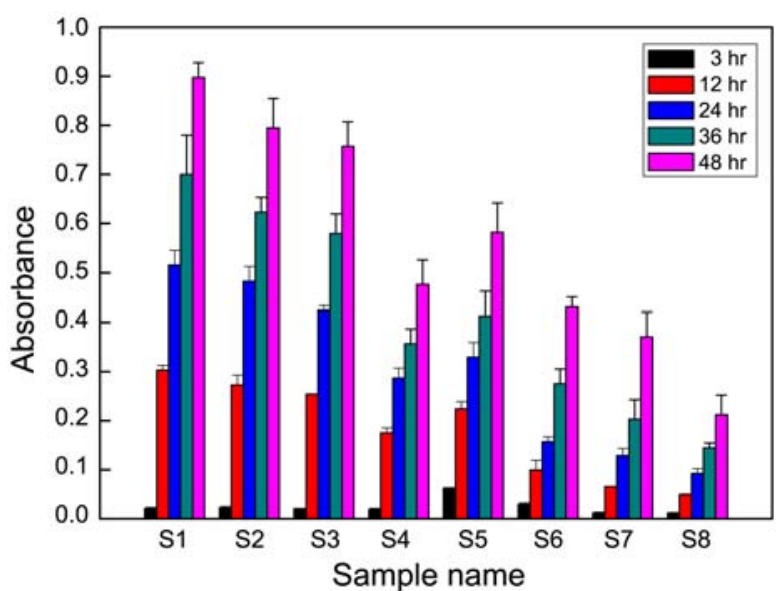

Figure 5. Antimicrobial activities of hydrogels for E. coli. during 48 hours.

to which various amounts of alginate and/or MAA were introduced, with respect to $S$. aureus and $E$. coli were investigated. The antimicrobial activities against $S$. aureus and $E$. coli were tested by observation of the cell growth in the absence and presence of various amount of alginate after two days of incubation. Figure 4 and 5 show the absorbance of the cells at $660 \mathrm{~nm}$ after two days of incubation in the presence of various concentrations of alginate and MAA for $S$. aureus and E. coli, respectively. The speed of growth of both cell decreased with increasing alginate. The speeds are also different by the presence of MAA, which is a negatively charged ion. The population of $S$. aureus in the presence of hydrogel without MAA (S1-S4) decreased by $18 \%$ after 36 $\mathrm{hr}$, and $12 \%$ after $48 \mathrm{hr}$. Whereas, in the presence of MAA containing hydrogel, the decreases were $43 \% 36 \mathrm{hr}$ after and $65 \%$ after $48 \mathrm{hr}$. Particularly, decrease in absorbance of S8 which contains MAA and $2 \%$ alginate was $83 \%$ compared to that in the absence of MAA and alginate. In the case of $E$. coli, decreases in absorbance were 40\% (48 hr) and 34\% (36 $\mathrm{hr}$ ) in the absence of MAA. The presence of MAA resulted in $37 \%$ (48 hr) and $27 \%$ (36 hr) decrease in cell population. These results clearly indicated that the inhibition hydrogel of cell growth differs cell by cell. The efficiency of inhibition of the $S$. aureus growth by hydrogel was far more significant in the presence of MAA compared to its absence and showed the tendency of more effective inhibition with increasing alginate concentration. Increasing the alginate concentration induces more effective antimicrobial activity. The effect of MAA was far less important in the inhibition of the E. coli growth by hydrogel. It was reported that the inhibition of cell growth by HEMA alone was more effective than that in the presence of MAA in the Staphylococcus epidermidis or Pseudomonas aeruginosa strains case, ${ }^{49-51}$ and HEMA alone adsorbed on the lens surface more effectively that HEMA plus MAA. However, base on the observation made in this study that the antibacterial activity increased when MAA was present, and furthermore, more alginate resulted in a lower absorbance, it is conceivable that decrease in absorbance is a result of increased antimicrobial 
effect by alginate rather than increasing of bacterial population that were attached. In summary, antibacterial effect of pHEMA increased in the presence of alginate. The introduction of anionic MAA inducing higher water content resulted in more enhanced antibacterial effect.

\section{Conclusion}

In this study, biocompatible, nontoxic, flexible polymer, pHEMA containing MAA and/or alginate were synthesized. The effect of introduced MAA and/or alginate on the antimicrobial activity and protein adsorption were also investigated. Adsorption of BSA protein is more effective with increasing amount of alginate disregarding in the presence of MAA. However, the presence of MAA enhanced the lysozyme adsorption in addition to the enhancement by alginate. Increasing the alginate concentration induces more effective antimicrobial effect. The presence of MAA further enhances the antibacterial effect. PHEMA-MAA/alginates are a promising candidate for good ocular biomaterials and contact lenses.

Acknowledgments. This work was supported by an internal research grant of Catholic University of Daegu and of Yeungnam University conferred to H. M. Lee and T. S. Cho, respectively.

\section{References}

1. Sokker, H. H.; Ghaffar, A. M. A.; Gad, Y. H.; Aly, A. S. Synthesis and Characterization of Hydrogels Based on Grafted Chotosan for the Controlled Drug Release; Carbohydr. Polym. 2009, 75, 222-229.

2. Piras, A. M.; Chiellini, F.; Fiumi, C.; Bartoli, C.; Fiorentino, B.; Faina, C. Int. J. Pharm. 2008, 357, 260-271.

3. Xiong, M. P.; Forrest, M. L.; Ton, G.; Zhao, A.; Davies, N. M.; Kwon, G. S. Biomaterials 2007, 28, 4889-4900.

4. Beyer, M.; Felgenhauer, T.; Bischoff, F. R.; Bretling, F.; Stadler, V. Biomaterials 2006, 27, 3505-3514.

5. Dini, L.; Panzarini, E.; Miccoi, M. A.; Miceli, V.; Protopapa, C.; Ramires, P. A. Tissue Cell 2005, 37, 479-487.

6. Chien, Y. W.; Lin, S. S. Clin Pharmacokinet 2002, 41, 1267-1299.

7. Yu, B.; Wang, C.; Ju, Y. M.; West, L.; Harmon, J.; Moussy, J. Y. Biosens. Bioelectron. 2008, 23, 1278-1284.

8. Hu, M.-X.; Yang, Q.; Xu, Z.-K. J. Membr. Sci. 2006, 285, 196-205.

9. Lou, X.; Munro, S.; Wang, S. Biomaterials 2004, 25, 5071-5080.

10. Rosso, F.; Barbarisi, A.; Barbarisi, M.; Petillo, O.; Margarucci, S.; Calarco, A.; Peluso, G. Mater. Sci. Eng. C 2003, 23, 371-376.

11. Lord, M. S.; Stenzei, M. H.; Simmons, A.; Milthorpe, B. K. Biomaterials 2006, 27, 567-575.

12. Koffas, T. S.; Opdahl, A.; Marmo, C.; Somorjal, G. A. Langmuir 2003, 19, 3453-3460.

13. Chhabra, P.; Gupta, R.; Suri, G.; Tyagi, M.; Seshadri, G.; Sabharwal, S.; Niyogi, U. K.; Khandal, R. K. Int. J. Polym. Sci. 2009; p 1-9 (Article ID 906904).

14. Sato, T.; Uchida, R.; Tanigawa, H.; Uno, K.; Murakami, A. J. Appl. Polym. Sci. 2005, 98, 731-735.

15. Alvarez-Lorenzo, C.; Concheiro, A. J. Chtomatogr. B 2004, 804, 231-245.

16. Alvarez-Lorenzo, C.; Hiratani, H.; Gomez-Amoza, J. L.; MartinezPacheco, R.; Souto, C.; Concheiro, A. J. Pharm. Sci. 2002, 91, 2182-2192.
17. Garrett, Q.; Laycock, B.; Garett, R. W. Biomaterials 2006, 27, 1341-1345.

18. Scheider, G. B.; English, A.; Abraham, M.; Zaharias, R.; Stanford, C.; Keller, J. Biomaterials 2004, 25, 3023-3028.

19. Hoffman, A. S. Adv. Drug Deliv. 2002, 43, 3-12.

20. Chen, S.; Liu, M.; Jin, S.; Chen, Y. J. Appl. Polym. Sci. 2005, 98 , $1720-1726$

21. La Gatta, A.; De Rosa, A.; Laurienzo, P.; Malinconico, M.; De Rosa, M.; Schiraldi, C. Macromol. Biosci. 2005, 5, 1108-1117.

22. La Gatta, A.; Schiraldi, C.; Esposito, A.; D’Agostino, A.; De Rosa, A. J. Biomed. Mater. Res. A 2008; p 292-302.

23. Quinn, K. J.; Courtney, J. M.; Evans, J. H.; Gaylor, J. D. S.; Reid, W. H. Biomaterials 1985, 6, 369-377.

24. Shi, B. J.; Nie, X.-H.; Chen, L.-Z.; Liu, Y.-L.; Tao, W.-Y. Carbohydrate Polymers 2007, 68, 687-692.

25. Hayashi, K.; Nakano, T.; Hashimoto, M.; Kanekieyo, K.; Hayashi, T. Int. Immunophar. 2008, 8, 109-116.

26. Wang, J.; Zhang, Q.; Zhang, Z.; Li, Z. Int. J. Biol. Macromole 2008, 42, 127-132.

27. Augst, A. D.; Kong, H. J.; Mooney, D. J. Macromol. Biosci. 2006, 6, 623-633.

28. Irmgard Behlau, M. D.; Michael, S.; Gilmore, Arch. Ophthalmol. 2008, 126, 1572-1581.

29. Nathan Efron et al., Contact lens Practice, Planta Tree: New Delhi, 2002; pp 71-80.

30. Refojo, M. F. Water imbibition Dabezies, O. H. Eds. Contact Lenses: The CLAO Guide to Basic Science and Clinical Practice, Grune and Stratton: New York, 1991, 9, 1-4.

31. Tighe, B. In: Phillips F. Speed well, Eds., Contact lens materials in contact lenses. Buterworth-Heinemann: Edinburgh, 2009; pp 5978.

32. Luensmann, D.; Jones, L. Contact Lens \& Anterior Eye 2008, 31, 179-187.

33. Xinming, L.; Yingde, C.; Lloyd, A. W.; Mikhalovsky, S. V.; Sandeman, S. R.; Howel, C. A.; Liewen, L. Contact Lens \& Anterior Eye 2008, 31, 57-64.

34. Garrett, Q.; Laycock, B.; Garett, R. W. Biomaterials 2006, 27, 1341-1345.

35. Sariri, R. J. Appl. Biomater \& Biomech. 2004, 2, 1-19.

36. Fleiszig, S.; Efran, M. N. J. Clin. Microbiol. 1992, 30, 1156-61.

37. Cook, A. D.; Sager, R. D.; Pitt, W. G. J. Biomater. Appl. 1993, 8, 72-89.

38. Portoles, M.; Refojo, M. F. Adv. Exp. Med. Biol. 1994, 350, 421-426.

39. Solomon, O. D.; Refojo, M. F.; Leong, F. L. Cornea 1999, 11, 47-52.

40. Luensmann, D.; Jones, L. Contact Lens \& Anterior Eye 2008, 31, 179-187.

41. Bohnert, J. L.; Horbett, T. A.; Ratner, B. D.; Roycet, F. H. Invest. Ophthal. \& Visual Sci. 1988, 29, 362-373.

42. Garrett, Q.; Chatelier, R.; Griesser, H. J.; Milthorpe, B. K. Biomaterials 1998, 23, 2175-2186.

43. Lord, M. S.; Stenzei, M. H.; Simmons, A.; Milthorpe, B. K. Biomaterials 2006, 27, 567-575.

44. Garrett, Q.; Laycock, B.; Garett, R. W. Biomaterials 2006, 27 , 1341-1345.

45. Gao, B.; Hu, H.; Guo, J.; Li, Y. Colloids and Surfaces B: Biointerfaces 2010, 77, 206-213.

46. Gao, B.; Fu, H.; Li, Y.; Du, R. J. Chromatogr B Analyt Technol. Biomed. Life Sci. 2010, 878, 1731-1738.

47. Allen, H. F. Ann Ophthalmol. 1971, 3, 235-246.

48. Feng, Q. L.; Wu, J.; Chen, G. Q.; Cui, F. Z.; Kim, J. O. J. Biomed. Mater. Res. 2000, 54, 662-668.

49. Fleiszig, S. M.; Evans, D. J.; Mowrey-McKee, M. F.; Payor, R.; Zaidi, T. S.; Vallas, V.; Muller, E.; Pier, G. B. Optom. Vis. Sci. 1996, 73, 590-594.

50. Cowell, B. A.; Willcox, M. D.; Schneider, R. P. J. of Appl. Microbiol. 1998, 84, 950-958.

51. Taylor, R. L.; Willcox, M. D.; Williams, T. J. J. Verran, Optomet. Vis. Sci. 1998, 75, 23-29. 